TESIS DOCTORAL La organización secuencial de las reparaciones en interacciones entre profesora y alumnos de español como lengua extranjera centradas en el significado: repercusión en la intersubjetividad y la competencia interaccional de los hablantes

(Batlle Rodríguez, 2015)

Disponible en http://www.tesisenred.net/handle/10803/390950

Directora: María Vicenta González Argüello

Recepción: 12/04/2018 | Revisión: 02/05/2018 | Aceptación: 02/05/2018

\title{
Laura ACOSTA ORTEGA
}

Universitat Pompeu Fabra

laura.acosta@upf.edu

La interacción oral en el aula de lenguas extranjeras/lenguas segundas ha supuesto un campo de estudio muy prolífico del que se han realizado investigaciones bajo diferentes perspectivas y con distintos propósitos. Desde el inicio de los 2000 han aumentado el número de estudios que analizan dicho contexto de aula bajo la mirada de Análisis de la Conversación. Este enfoque permite realizar un análisis detallado de las acciones que llevan a cabo los participantes (es decir, docentes y estudiantes) en un contexto en el que cada turno de habla abre una nueva posibilidad de aprendizaje. En dicha perspectiva se analizan, entre otros temas, cómo se gestiona la interacción mediante la toma de turnos de habla, cómo se crea alineamiento entre los participantes, cómo se construyen identidades y cómo se solucionan los problemas en la interacción.
Este último concepto, denominado reparación, es el objeto de análisis de la tesis doctoral del Dr. Jaume Batlle. Bajo el título "La organización secuencial de las reparaciones en interacciones entre profesora y alumnos de español como lengua extranjera centradas en el significado: repercusión en la intersubjetividad y la competencia interaccional de los hablantes", el investigador analiza de forma detallada qué ocurre cuando surge un problema en la interacción entre docente y estudiante, abordando qué se repara, cómo se repara y cómo se recupera el hilo de la interacción en curso. De este modo, el estudio arroja luz sobre un área que no se había explorado en el campo del español como lengua extranjera, hecho que permite que los profesores de este ámbito puedan indagar para mejora su actuación docente. 
Taly como se anuncia en laintroducción de la tesis, a lo largo de su trayectoria docente, el Dr. Jaume Batlle ha sentido predilección por la interacción oral, hecho que le ha empujado a adentrarse en los estudios realizados sobre el discurso en el aula y, finalmente, a analizar en profundidad qué ocurre cuando los docentes y los estudiantes interactúan.

El objetivo general de la tesis del Dr. Batlle es el de analizar las trayectorias de las secuencias de reparación producidas en las interacciones entre profesor y alumno centradas en el significado para determinar cómo se restablece la intersubjetividad entre los interlocutores. Para ello, en primer lugar, se caracteriza cada una de las técnicas de reparación que se producen; en segundo lugar, se analiza qué implicaciones se establecen entre las diferentes secuencias de reparación con la recuperación de la secuencia interaccional que se estaba produciendo antes de la señalización del problema; y, en tercer lugar, se busca caracterizar la competencia interaccional en el aula en las reparaciones producidas.

La estructura del trabajo doctoral presenta los apartados que caracterizan toda investigación. En primer lugar, el doctor se fundamenta en un marco teórico en el que se recoge, con una mirada crítica, las diferentes teorías y enfoques que se ha aplicado en los trabajos que le han precedido. La bibliografía recogida es extensa y minuciosa y convierte el trabajo doctoral del Dr. Batlle en una obra indispensable de consulta para cualquier investigador que quiera adentrarse en los conceptos básicos del Análisis de la Conversación y de la interacción en el aula de lenguas extranjeras. Las obras consultadas y referenciadas incluyen desde los estudios clásicos necesarios para entender la perspectiva que se ha adoptado en la investigación, hasta las referencias más actuales sobre este campo. Por ello, aporta al lector una mirada amplia al campo de estudio y permite apreciar la relevancia del análisis realizado por el autor.

Respecto a la metodología utilizada para realizar el análisis, el autor explicita las particulares de las investigaciones llevadas a cabo bajo la perspectiva del Análisis de la Conversación. Por ejemplo, señala la importancia del análisis realizado desde la mirada detallada de lo que ocurre en la interacción (perspectiva émica), frente a otros enfoques en los que se observa la realidad desde fuera (perspectiva ética). Asimismo, se describe meticulosamente el contexto de recogida de datos, el método utilizado para el registro de los mismos, los informantes que participaron, las interacciones recogidas, el modo en el que se transcribieron los datos y las categorías de análisis utilizadas. Hay que destacar la importancia de los anexos en esta investigación, que nos acercan al análisis realizado y aportan fiabilidad a la investigación.

En el análisis de los datos se clasifican las reparaciones según quién las inicia (el hablante u otro participante) y se observa qué ocurre si quien inicia estas reparaciones es el docente o el alumno. Además, se observa qué tipo de acción comunicativa subyace a la reparación. Durantelas páginas dedicadas al análisis de los datos, el autor describe qué ocurre en cada una de las secuencias de reparación que surgen en la interacción y, mediante el análisis de estos ejemplos, realiza una caracterización detallada y minuciosa del objeto de estudio. De este modo, siguiendo los 
principios del Análisis de la Conversación, el investigador no se centra únicamente en aquellos casos más habituales en sus datos, sino que analiza también aquellos que se consideran únicos, lo que permite al lector tener una visión completa del fenómeno analizado.

Como conclusiones, se observa en las interacciones que todas las reparaciones se ven representadas en los datos, aunque algunas con más presencia que otras; dato que se relaciona con el tipo de interacción institucional objeto de estudio. En el análisis, se observa que el rol del docente resulta en una tendencia a solucionar los problemas en la interacción o a provocar que los estudiantes solucionen sus problemas. Respecto a la recuperación de la intersubjetividad en la interacción, el autor concluye que el rol de los participantes resulta significativo a la hora de restablecer la interacción: por ejemplo, se observa que el docente la retoma si las reparaciones tienen un objetivo metalingüístico o pedagógico.

$\mathrm{El}$ autor finaliza la tesis reflexionando sobre las implicaciones pedagógicas que surgen de esta investigación. Señala que, si el docente desea que los estudiantes también reparen en la interacción y retomen la interacción tras estas secuencias, debe facilitar una participación que no se base en turnos de habla que proyecten únicamente corroboraciones por parte de los alumnos. Mediante la caracterización que el investigador realiza de las reparaciones en las interacciones entre docente y estudiante, se plantea si en las interacciones de aula se está ayudando a los estudiantes a desarrollar su competencia interaccional, es decir, a mejorar cómo los estudiantes se manejan en la interacción oral.

La tesis, defendida el diecisiete de diciembre de 2015, obtuvo una cualificación de cum laude y el Premio Extraordinario de Doctorado de la Facultad de Educación de la Universidad de Barcelona. Cabe también, desde aquí, hacer extensivas las felicitaciones a la directora de la tesis, la Dra. Vicenta González Argüello. 